\title{
Fluidized Bed Combustion: Technology for Efficient Utilization of Biomass Residues
}

\author{
Vishal Sharma and Rajeev Kamal Sharma \\ Department of Mechanical Engineering, Chitkara University Institute of Engineering \& Technology, Rajpura, Punjab, India \\ E-Mail: vishal.s@chitkara.edu.in
}

\begin{abstract}
Fossil fuels are the most common and reliable energy source, which presently fulfill $80 \%$ energy requirements all across the world. In the last few decades, over-consumption, fast pace modernization and population growth are some prominent factors which are exploiting the fossil fuels. The degradation of natural resources has gone up at an alarming rate which provoked to look for an alternate source of energy. From all available alternative renewable energy sources, biomass is the only carbon-based sustainable option. But, its diversity makes it a complex and difficult fuel. Among all technologies used for energy generation from the biomass, fluidized bed combustion is emerging as a suitable best option to handle fuel diversity. This article deals with biomass fluidization and its combustion in a fluidized bed. The difficulties encountered during biomass combustion and different solutions for the same have been highlighted. Problems like deposition, corrosion, agglomeration and trace metal emission have been discussed and their remedies to avoid the discontinuity in the operation of biomass-fired fluidized bed combustor. This technical approach will help to reduce environmental problems, improve the economic structure of the nation, and remove obstacles for sustainable energy development.
\end{abstract}

Keywords: Biomass, Fluidized Bed Combustion, Biomass Utilization Technologies

\section{INTRODUCTION}

There are many natural energy resources present on the earth out of which fossil fuels are the most attractive and are providing a great source of energy. Fossil fuel always played a crucial role to meet the energy demand and still has the potential to fulfill about $84 \%$ of energy demand by 2030 [1]. An exceeding energy demand, fast pace modernization, overpopulation, overconsumption, population growth, and industrialization are deteriorating fossil fuel sources at a very faster rate [1-2]. The world energy consumption is increasing at $1.1 \%$ per year and would reach 736 quadrillions BTU by 2040 [3]. In the course of the most recent couple of decades, the misuse of natural sources on the planet and the degradation of the environment have gone up at the alarming rate [4] Due to this, human beings and their environment are contaminated by the continuous and accelerating use of fossil fuels [5]. Frightening environmental conditions by combustion of fossils oversight the researchers to think about an alternative source which must be sustainable and renewable [6-7].

Sustainable power sources are raising as a decent option in contrast to the non-renewable energy sources. Sustainable power source asset contributed $14 \%$ of the world's energy utilization. Among all sustainable power sources like solar, geothermal, wind, tidal, hydro and biomass, biomass is featured as the huge source of energy and is accessible in abundance in an agricultural country like India [7-9]. Biomass is the form of the renewable and sustainable source of energy obtained from the agriculture waste, forestry waste, municipal waste, biofuels, liquid biofuel, etc. [10-11]. Biomass is exceptionally perfect and clean source of energy which contributes $9.5 \%$ of the total contribution by renewable energy sources [12-11]. Prior, an extensive proportion of the biomass was non-commercial and little amount was utilized for cooking and warming purposes. But over the last few decades, biomass has made a space in industrial applications for the production of electricity [13-14]. Biomass offers a befitting response to all environmental issues due to excessive use of fossils. Biomass is the carbon-neutral renewable energy source. It does not lead to a net increment of the greenhouse gases in the atmosphere [15-16]. Biomass is the oldest fuel which is available in all parts of the world. Energy produced by biomass faced with some serious problem. A few of them are cost, transportation, high moisture content, diversity in shape and size, composition, seasonal availability, low efficiency (low grade), and lag in utilization techniques and methods. These are some current challenges of biomass utilization. The effective biomass utilization technologies are really needed to address these challenges. Accordingly, in the last few decades, some intensified utilization methods for biomass have been developed for sustainable growth. Among the possible technologies for treating biomass, fluidized bed combustion has received the wide attention of researchers.

The present paper focuses on the issues and problems in fluidized bed combustion technology. The focal point of the present study is to provide more information related to some serious issues in the combustion process during the thermochemical conversion of biomass. It includes NOx, $\mathrm{N} 2 \mathrm{O}, \mathrm{SO} 2$, dust particles, agglomeration, ash related problem, and corrosion. The impact of the chemical and physical properties of biomass on the burning procedure and emission qualities has been discussed.

In section 2, biomass, its properties, and biomass classification approaches have been discussed. Section 3 shows the different methods and techniques of utilizing 
biomass and the issues occurred during thermochemical conversion followed by the major problems in the fluidized bed combustion $\mathrm{viz}$. deposits, corrosion, agglomeration and trace metal emission.

\section{BIOMASS CLASSIFICATION AND ITS ENGINEERING PROPERTIES}

Biomass is an organic matter or biological material- (wood, animal waste, and plant residue) that can be utilized as an energy source. It is the most flexible energy source. Biomass is the mature type energy after sun-based energy. Fuelwood is the most well-known form which has been utilized since ancient time. Subsection 2.1 provides the classification of the biomass from literature [17-19]. Subsection 2.2 and subsection 2.3 have discussed the biomass composition and its engineering properties used for design and smooth operation purpose.

\section{A. Biomass Classification}

There are many ways to classify biomass. Some of them are as follow:

\section{Classification based on the usage [17]:}

1. Primary waste- non-edible part of food crops and forest product (wood, straw, cereals, maize husk, etc.).

2. Secondary waste- process waste (sawdust, food industry waste, paper mills waste, apricot seeds, bravery industry waste, etc.).

3. Tertiary waste- a by-product of used biomass (demolished wood, waste).

Classification based on the origin of biomass [18].

1. Forestry waste- wild grass, chips, bark fruit, skull, woody residue, twigs, herbaceous, etc.

2. Agriculture waste- oil-producing plants, aquatic plants, weeds, crop waste, etc.

3. Livestock- municipal waste, sewage sludge, food industries waste, animal waste, etc.

Based on the properties [18]:

1. Wood and woody fuel (hard and softwood, demolition wood, etc.).

2. Herbaceous fuels (straw, grasses, stalks, etc.).

3. Wastes (sewage sludge, refuse-derived fuel (RDF), etc.).

4. Derivate (waste from paper and food industries, etc.).

5. Aquatic (Kelp, algae, etc.).

6. Energy crops (specifically cultivated for energy purposes).

Based on energy resources [19]:

1. Conventional agricultural waste biomass

a. Agriculture resources- (food, material, etc.). b. Forestry resources- (pulp, chips, etc.).

c. Marine resources- (food, material, etc.).

d. Livestock resources- (foods, municipal, etc.).

2. Waste biomass

Agriculture, forestry, industrial waste, etc.

3. Plantation biomass

a. Tree biomass- (poplar, palm, etc.).

b. Herbage- (switchgrass, sugarcane, etc.).

c. Marine biomass- (seaweed, plankton, etc.).

Based on the biofuel origin and source [19]:

1. Woody biomass (wood chips, pellets, logwood, sawdust, etc.).

2. Herbaceous biomass

3. Fruit biomass

4. Blend and mixtures.

Due to the diversity in the biomass, their classifications vary in a wide range. Apart from the above biomass can also classify based on the chemical composition, volatile nature of biomass, high heating value, etc.

\section{B. Biomass Composition}

The components of biomass include ash, hydrocarbon, starches, sugar, protein, lignin, cellulose, hemicellulose and other components. The quantity of each component varies from species to species, climatic condition, various types of plant, growing condition, etc. Prescribed methods are used to determine elemental composition and chemical biology of the biomass. These methods are (1) proximate analysis helps to classify the fuel in terms of its volatile matter (VM), fixed carbon (FC) and ash content; and (2) ultimate analysis demonstrates the elemental composition in term of carbon $(\mathrm{C})$, hydrogen $(\mathrm{H})$, nitrogen $(\mathrm{N})$, sulphur $(\mathrm{S})$ composition and oxygen $(\mathrm{O})$ very often by difference in the solid fuel. Generally, the dry weight percentage of carbon, hydrogen, oxygen, nitrogen, sulphur, and chlorine are $30 \%$ to $60 \%, 5$ to $6 \%, 30$ to $45 \%$, and rest usually less than $1 \%$ respectively [20].

TABle I Proximate ANALYSis Data OF SELECTED Biomass MATERIALS (\%, DRY BASIS BY WEIGHT) FROM THE LiTERATURE

\begin{tabular}{|l|c|c|c|}
\hline Biomass type & & \multicolumn{2}{|c|}{ Proximate analysis } \\
\hline & VM & FC & Ash \\
\hline Cotton stalk & 65.86 & 15.77 & 4.48 \\
\hline Switchgrass & 80.4 & 14.5 & 5.1 \\
\hline Bagasse & 85.50 & 12.4 & 2.1 \\
\hline Wood residue & 78 & 16.6 & 5.4 \\
\hline Forest residue & 79.9 & 16.9 & 3.2 \\
\hline Sunflower & 76 & 20.9 & 3.1 \\
\hline
\end{tabular}

The proximate analysis and ultimate analysis of the few biomass samples from the literature are shown in Table I and Table II respectively. Apart from this, some heavy metal like lead, cadmium etc. are generally found in woody fuels. 
TABle II Ultimate Analysis Data Of Selected DRy Biomass Materials (\%, Dry Basis By Weight) From Literature

\begin{tabular}{|c|c|c|c|c|c|}
\hline \multirow[t]{2}{*}{ Biomass type } & \multirow[b]{2}{*}{$\mathbf{C}$} & \multicolumn{3}{|c|}{ Ultimate analysis } & \multirow[b]{2}{*}{$\mathbf{S}$} \\
\hline & & O & $\mathbf{H}$ & $\mathbf{N}$ & \\
\hline Cotton stalk & 41.3 & 39.7 & 6.8 & 0.7 & 0.5 \\
\hline Switchgrass & 49.7 & 43.4 & 6.1 & 0.7 & 0.11 \\
\hline Bagasse & 49.8 & 43.9 & 6.0 & 0.2 & 0.06 \\
\hline Wood residue & 51.8 & 41.9 & 6.1 & 0.5 & 0.08 \\
\hline Forest residue & 52.7 & 41.1 & 5.4 & 0.7 & 0.10 \\
\hline Sunflower & 50.4 & 43.0 & 5.5 & 1.1 & 0.03 \\
\hline
\end{tabular}

\section{Biomass Engineering Properties}

Engineering properties of biomass are critical for the operation and design reason. These properties incorporate bulk density, particle size, color, moisture content, ash fusion point, particle density, high heating value, ash content, low heating value, and flowability. Biomass is a characteristic asset that displays heterogeneity in structure and compound arrangement. A profound comprehension of its physical properties, chemical properties, and quick equipment for describing these properties are required for the engineering designs and safe operations.

\section{CONVERSION TECHNIQUES AND METHODS FOR UTILIZING BIOMASS}

Biomass is the world's most copious natural organic material and it can possibly meet the world's surpassing energy requirement. However, the change of biomass materials to biofuels (used as bio-energy) is more typical and expensive. So the coming subsection 3.1 shows currently available type of conversion methods. These methods are resulting in specific energy products. Biomass utilizing techniques and issues in thermochemical conversion have been discussed in subsection 3.2 and subsection 3.3.

\section{A. Biomass Conversion Methods}

Following are some method available for biomass conversion:

1. Physical Conversion of Biomass: In the physical conversion of biomass, the raw wood biomass materials are changed into high storage form and easy transportation form by harvesting, pelletizing and briquetting. It is further used for heating and cooking purposes.

\section{Thermochemical Conversion of Biomass:} Thermochemical conversion techniques are used for converting biomass into biofuel. It involves various stages. Initially, biomass is converted into gas then into oils. Finally, the oils are conditionedand synthesized to produce syngas which is utilized as the fuel. This process includes processes like combustion, gasification, and pyrolysis etc.
3. Biochemical Conversion of Biomass: The biochemical change includes the utilization of chemical agents to change over biomass into fluid fuels. It includes the utilization of microscopic organisms, microorganisms, and compounds to separate biomass matter into vaporous or fluid fuels, for example, biogas or bioethanol. The most wellknown biochemical advancements are anaerobic digestion (or biomethanation) and fermentation.

\section{B. Biomass Utilizing Techniques}

Some of the techniques used to utilize the biomass are as follows

Combustion is a perplexing procedure, comprised of some fundamental advances incorporate de- volatilization, gasification, drying, char combustion, and gas phase reactions. Residential stoves, heaters, and boilers are changing over the biomass into the valuable energy to create heat for different means. Co-firing is the burning of a nonrenewable energy source, (for example, natural gas, petrol, and coal) along with a biomass feedstock which has various points of interest are

1. It changes over poor quality biomass deposits into highreview fuel.

2. Less emission of the sulphur, carbon dioxide, and other greenhouse gases with little modification.

3. Helps to convert biomass waste into energy.

Pyrolysis and torrefaction are the processes by which energy does not produce directly from biomass. But under certain controlled conditions of temperature and pressure with a limited amount of oxygen, these processes convert biomass feedstocks into gas, oil or forms of biochar or charcoal. In these processes, biomass undergoes partial combustion at a temperature greater than $430{ }^{\circ} \mathrm{C}$ in pyrolysis and temperature of $200-320{ }^{\circ} \mathrm{C}$ in the torrefaction. Pyrolysis results in the solid and liquid residue generally known as biochar, charcoal, and other by-products are methanol, tars, oils, acetone, etc. In the torrefaction process, the chemical components of the biomass such as lignin, cellulose, and hemicellulose are converted into biochar (high-grade fuel).

Gasification is another method to convert the biomass residue into producer gas and charcoal, followed by some heterogeneous and homogeneous chemical reactions. It is achieved by reacting the biomass residue at a high temperature above than $800{ }^{\circ} \mathrm{C}$ without combustion (controlled amount of oxygen). It results in the highly efficient syngas has high heat output as compared with direct combustion. Further, it is used directly in the gas engines, used to produce hydrogen and methanol. It converts a wide range of organic material in synthetic fuel.

Fluidization is an outstanding Engineering process. At present, fluidized bed combustion (FBC) is emerging as the most promising energy source amongst the other processes by thermochemical transformation of biomass 
[21]. FBC is a technique in which solids are caused to act as a liquid by blowing gas or fluid upwards through the strong filled combustor. This system is broadly utilized in business activities; the application can be generally ordered into two classes, i.e. * Physical activities, (for example, transportation, warming, assimilation, blending of fine powder, and so forth.) and * Chemical activities, (for example, responses of gases on strong impetuses and responses of solids with gases and so on.)

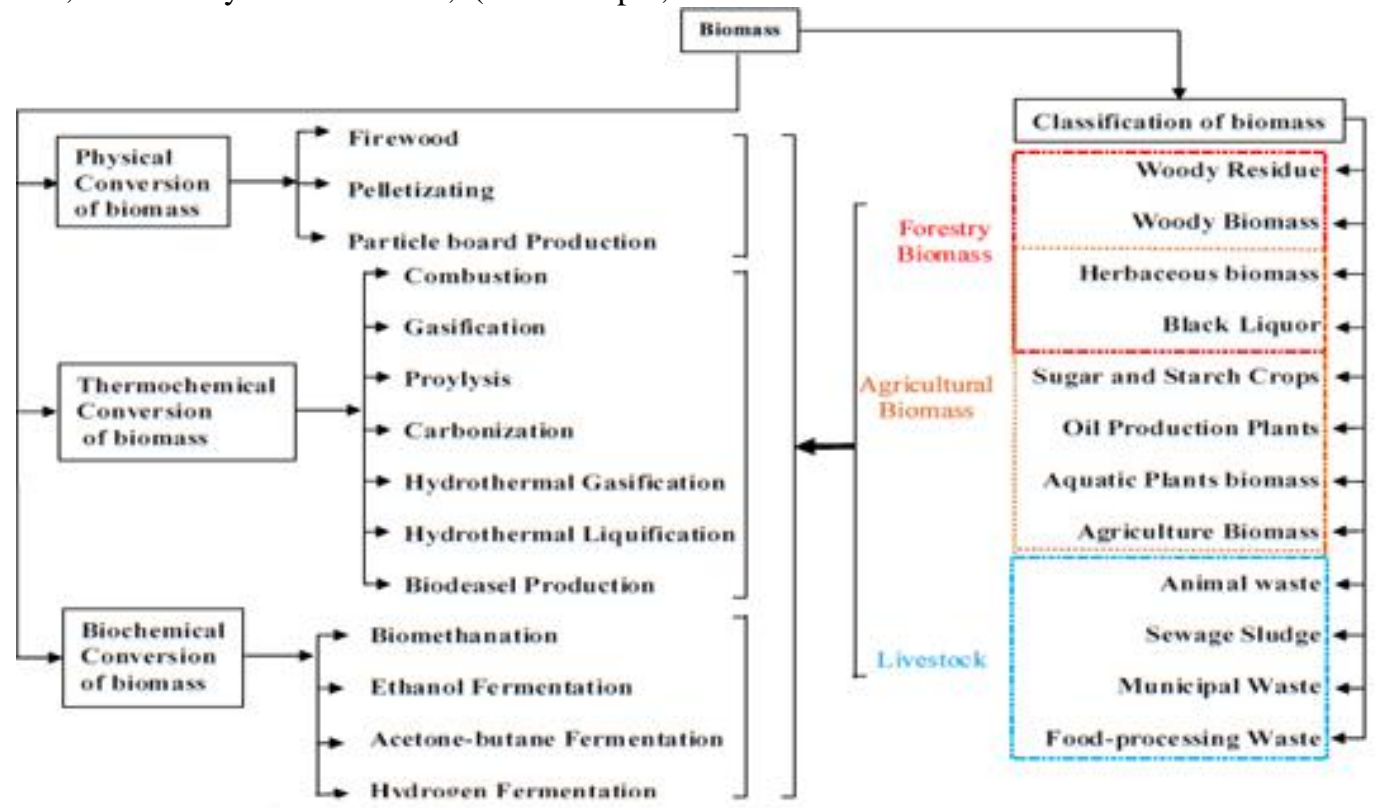

Fig. 1 Classification of conversion methods and general biomass [11, 17-19]

The fluidized bed combustion is one of the best method known as contacting techniques utilized in industry. The few fundamental focal points are:

1. Well blended prompting low - temperature inclinations.

2. Suitable for both little and vast scale tasks.

3. Continuous processing.

Fluidization process applications are also well recognized in nuclear engineering for reprocessing of fuels, uranium extraction, nuclear fuel fabrication, and waste disposal.

\section{Issues During the Thermochemical Reaction in FBC}

Homogenously and the smoothly operated fluidized bed gives the efficient results, but many factors are affecting the thermochemical reaction during the fluidization process. Agglomeration and improper fluidization are the factors may lead to bed collapse [22]. Operational problems in biomass combustion- Complete combustion of the biomass are very important for high output (heat) and low emission level. It fundamentally relies upon the combustion chamber temperature, size of bed material, type of bed material, the open area distributor plate, fluid velocity, the drag force on the particulates, load conditions, etc. Nature and the conditions at which the operational problems occurred with biomass mainly depend upon the choice of the combustion technology. Some of the major problems are the disposal of ash, corrosion of metallic part, fire unit deposition etc. Especially, in fluidized bed combustion, the biomass consists of alkali metals which are the main cause of agglomeration of the bed material [23]. Further, it causes serious problems for biomass to use as a fuel. Major problems occur in the fluidized bed combustion are as follow

1. Deposits and corrosion

2. Agglomeration

3. Trace of metal emission

Deposition, corrosion, agglomeration, and a trace of metal emission are precisely related to the composition of the biomass. The presence of chlorine, potassium and alkali compounds in biomass leads to deposition or corrosion of metallic parts and agglomeration de-fluidized the fluidized bed. To operate the FBC in a continuous and efficient manner, there is the need to maintain the combustion chamber temperature. This can be maintained by the continuous stream of air flow which creates turbulence in the mixed bed of fuel and particulate bed material. This can provide the mixing of bed material and instant heat transfer [24]. But, in order to avoid agglomeration problem in fluidized beds, it is operated at the lower temperature which affects the combustion efficiency. Higher the bed temperature, rapid agglomeration tendency, and huge agglomerates

\section{Deposits and Corrosion}

Deposits in combustion are the layers of ash particles or materials gathered on the surface of heat exchanger 
equipment or furnace wall or other uncovered parts. Corrosion is the oxide layer formed on the surface of the metal due to response to various environmental conditions. It tends to be caused by the response gas reaction in the heat chamber [25]. Deposits and corrosion reduce the heat transfer rate and also reduce the lifetime of the equipment. Biomass materials contained potassium, silica, sodium, other alkali components, ash, and moisture content, which have an important role in the deposition and corrosion process [26]. Biomass operated fluidized bed combustors deposits have a high percentage of Calcium, silicon,chlorine, and potassium. Chlorine (38\% by weight) in biomass, largely found in the corrosion deposits which is affected by various condition includes: temperature and concentrations of other components as shown in Figure 2 [25, 27-29]. From the literature, It has been found that $\mathrm{Cl}$ is the major cause of the issues concerned with the corrosion occur at metallic parts of combustors temperature ranging from $450^{\circ} \mathrm{C}$ to $900^{\circ} \mathrm{C}$ [29-32].

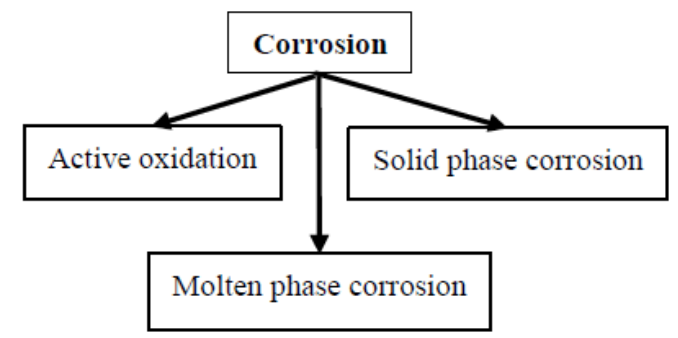

Fig. 2 Classification of the corrosion processes in biomass-fired boilers [33-34]

There are a few remedies available in the literature to hinder the effect of biomass elements in deposits and corrosion [33-36]. The presence of the different quantity of potassium, chlorine, and sulfur, have influenced the working of fluidized bed combustors [15, 33]. Leaching is one of the methods of removal of elements from biomass fuels with the help of water. It also reduces the alkali index and volatilization of inorganic species at about $500^{\circ} \mathrm{C}$ [34]. Another essential way to avoid deposits and corrosion effects on metallic equipment of fluidized bed combustor is to increase the melting point of alkali compounds relative to alkali chlorides. This has been done by using additives such as limestone, bauxite, kaolinite, magnesium oxide and other additives. During the combustion of biomass, these additives increase the melting point of ash that help to liberate the elements in the gas phase [28, 33].

\section{Agglomeration}

Agglomeration is one of the potential issue concern with biomass burning in fluidized bed combustion. It leads to spontaneous shutdown of the working plant. During the combustion process, when the small portion of the ash contains remains in the bed, mainly cause of agglomeration issues. The agglomerates of potassium, calcium, silicon, and aluminum have been mainly found in the biomass-fired plants [35-39]. The classifying mechanisms distinguished for ash agglomerates has appeared in Figure 3. Agglomeration is the cluster of melting salts (potassium and phosphorous), and the presence of silica and calcium from sand and fuel respectively. At the low- temperature potassium phosphate form silicates of potassium and calcium by reacting with silica, while calcium reacts with the phosphorous [33]. This is the primary issues happened in the biomass-fired combustors.

Remedies available in the literature to deal with the agglomeration issues are the utilization of additives, leaching of biomass, co-combustion, and use of alternatives bed material (i.e. feldspar, ferric oxide, alumina, magnesite, dolomite, and aluminum- rich minerals). The main motive of all remedies is to avoid agglomeration by varying the melting point of the ash content or sintering components. Other problems related to these bed material is high attrition, high entrainment rate, and chemical instability [40-42].

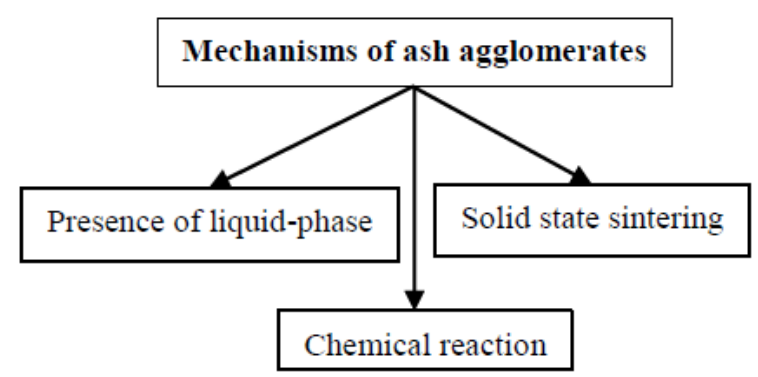

Fig. 3 Various processes recognized for ash sintering [15, 36]

\section{Trace of Metal Emission}

Biomass-fired fluidized bed combustors have another huge problem related to the emission of metals. Ash and exhaust consist of the trace of elements such as $\mathrm{Pb}, \mathrm{As}, \mathrm{Ni}, \mathrm{Mn}, \mathrm{Sb}$, $\mathrm{Ba}, \mathrm{Cd}, \mathrm{Mo}, \mathrm{Co}, \mathrm{Cr}, \mathrm{V}, \mathrm{Cu}, \mathrm{Zn}, \mathrm{Hg}$, and V). These trace of metals in biomass fuels have some public health issues. Agricultural residues contain a few traces of $\mathrm{Cd}$, which affect the kidney and bone density. The trace of different metals in the biomass is totally depended upon the type of biomass, an age of the biomass plants, developing sites, postprocessing of the biomass (such as pulverization wood, treated wood, etc.). Many researchers studied the effect of the different heavy metal trace on the environment and health.

Adsorbent material used in the fluidized bed which react with the heavy metals and react with them. Finally removed as the ash content. Example of the adsorbents material alumina, kaolinite, bauxite, and emathlite can react with these heavy metals. Some another way is absorption and chemical reaction in which heavy metal trace such as cadmium and lead are removed during the process. Example of some absorption material is: actuated carbon or other appropriate sorbents, post-precipitation, ion exchange, etc. This material applied externally to remove heavy metal trace in the form of metal concentrated ash. Finally, this 
heavily concentrated as is disposed of as a land filler is another effective measure [4]. There is not any fixed or proper method available in the literature to avoid small trace of metal emission [43]. The authors filtered the metalenriched ash and primary measure it to prevent metal enrichment in the emission [43]. Leaching of biomass also reduces the metal emission [34]. Use of additives to absorb the heavy metals in the bed which suppresses the volatilization of the trace of metals emission in the atmosphere [41, 44].

\section{CONCLUSION}

Biomass has a huge energy potential.it is a carbonneutral sustainable energy source. Biomass can assume an imperative role in future energy supply. It has a huge energy potential and is regarded as the promising source of energy for future thermal applications. There are numerous ignition techniques available for biomass burning, out of fluidized bed burning has been discovered one of the best technique to deal with biodiversity and upgrade the lowgrade fuel to high-grade fuels. It has been found that biomass combustion provides a positive edge to the hazardous emission of gases such as $\mathrm{CO}, \mathrm{CO}_{2}, \mathrm{NO}_{2}, \mathrm{SO}_{2}$, and $\mathrm{CH} 4$. Some other positive environmental and social impact reduces the use of fossil fuels and provide job opportunities. In the present paper, various aspects of biomass have been discussed related to combustion in fluidized bed combustion plants. Agglomeration, small traces of metal emission, corrosion are some problem associated with the burning of biomass in fluidized bed combustion. Biomass has a varying amount of chemical composition. These compositions have unique fundamental characteristics that help to characterize and determine the properties, potential thermal applications and its environmental impacts related to the biomass. he forthcoming of biomass in energy supply become bright for future thermal industrial applications. Future energy demand has to be fulfilled by biomass in sustainable ways. Many authors have concluded that there is a need for research and development to make biomass globally acceptable. The use of biomass will commit the better tomorrow in term of environmental benefits offered by it.

\section{REFERENCES}

[1] British Petroleum, "BP Statistical Review of World Energy 2007”, June, pp. 1-48, 2007.

[2] Annual BP Report, "Our key priorities Safety People Performance", Rev. Lit. Arts Am., 2007.

[3] U.S. Energy Information Administration, "International Energy Outlook 2017”, Int. Energy Outlook, Vol. IEO2017, pp. 143, 2017.

[4] B. K. Sovacool, R. J. Heffron, D. McCauley and A. Goldthau, "Energy decisions reframed as justice and ethical concerns", Nat. Energy, Vol. 1, pp. 16-24, 2016

[5] C. Vernon, and E. Thompson, "Carbon dioxide emission scenarios: limitations of the fossil fuel resource", Procedia Environ. Sci, Vol. 6, pp. 206-215, 2011.

[6] S. Shafiee, and E.Topal, "When will fossil fuel reserves be diminished?", Energy Policy, Vol. 37, No. 1, pp. 181-189, 2009.

[7] J. Popp, Z. Lakner, M. Harangi-Rákos, and M. Fári, "The effect of bioenergy expansion: Food, energy, and environment", Renew. Sustain. Energy Rev., Vol.32, pp. 559-578, 2014.

[8] M. H. Ramage, "The wood from the trees: The use of timber in construction", Renew. Sustain. Energy Rev, Vol. 68:p. 333-359, 2017.

[9] G. S. Alemán-Nava, "Renewable energy research progress in Mexico: A review", Renew. Sustain. Energy Rev, Vol. 32, pp. 140-153, 2014.

[10] J. Ministry of Agriculture, Forestry, and Fisheries, "The Asian Biomass Handbook Support Project for Building Asian-Partnership for", Japan Inst. Energy, pp. 338, 2008.

[11] N. L. Panwar, and N. S. Rathore, "Potential of surplus biomass gasifier based power generation: A case study of an Indian state Rajasthan", Mitig. Adapt. Strateg. Glob. Chang, Vol. 14, No. 8, pp. 711-720, 2009.

[12] M. F. Demirbas, M. Balat, and H. Balat, , "Potential contribution of biomass to the sustainable energy development", Energy Convers. Manag, Vol. 50, No. 7, pp. 1746-1760, 2009.

[13] Ministry of New and Renewable Energy, "No Title". [Online]. Available: $\quad$ https://mnre.gov.in/file-manager/annual-report/20152016/EN/Chapter 1/chapter_1.html.

[14] "MNRE". [Online]. Available: https://web.a rchive.org/web/20180 503151432/http://mnre.gov.in/p hysical-progress-achievements.

[15] A. A. Khan, Jong, W. de, P. J. Jansens, and H. Spliethoff, "Biomass combustion in fluidized bed boilers: Potential problems and remedies", Fuel Process. Technol, Vol. 90, No. 1, pp. 21-50, 2009.

[16] "ORC-main".

[17] G.H. Williams, "Fuel from biomass", Chem. Eng. News, Vol. 70(47, pp. 3-3, 1992.

[18] T. R. M. B.M. Jenkins, L.L. Baxter, T.R. Miles Jr., "Combustion properties of biomass", Fuel Process. Technol, Vol. 54, No. 1-3, pp. $17-46,1998$.

[19] H. Eet-kb, Energy, R., Technologies, U. and Energy, B., "Biomass", 2018, pp. 7-8.

[20] D. Ouwens, "Gasification of biomass and residues for electricity production Pergamon", 1997.

[21] R. Van den Broek, A. Faaij, and van A. Wijk, "Biomass combustion for power generation", Biomass and Bioenergy, Vol.11, No. 4, pp. 271-281, 1996.

[22] J. Y. T. Lipsanen, T. N. H. Räikkönen, O. Antikainen, "Particle Size, Moisture, and Fluidization Variations Described by Indirect Inline Physical Measurements of Fluid Bed Granulation", AAPS PharmSciTech, Vol. 9, No. 4, pp. 1070-1077, 2008.

[23] H. Kassman, "Strategies to Reduce Gaseous $\mathrm{KCl}$ and Chlorine in Deposits during Combustion of Biomass in Fluidised Bed Boilers", Ph.D, 2012.

[24] S. Suranani, and V. R. Goli, "Fuel Particle Size Effect on Performance of Fluidized Bed Combustor Firing Ground Nutshells", Int. J. Chem. Eng., pp. 147-151, 2016.

[25] H. P. Nielsen, F. J. Frandsen, Dam-Johnson, K. and Baxter, L.L., "the imlimentations of chlorine- associated corrosion on the operation of biomas- fired boilers", progress in energy and combustion science, Vol. 26, pp. 283-298, 2000.

[26] L. L. Baxter, "influence of ash deposit chemistry and structure on physical and transport properties", Fuel Processing Technology, Vol. 56, No. 1-2, pp. 81-88, 1998.

[27] L.L. Baxter, T. R. Miles, Jenkins, B. M., Milne, T., Dayton, D., "ihe behavior of the inorgic material in biomass-fired power boiler:field and lacoratory experiences", Fuel Processing Technology, Vol. 54, No. 1-3, pp. 47-78, 1998.

[28] T. R. Miles, T. R. J. Miles, L. L. Baxter, Bryers, R. W., Jenkin, B. M. and Oden, L. L., "Boiler deposits from firing biomass fuels", biomass and bioenergy, Vol. 10, pp. 125-138, 1996.

[29] J. Stringer, and A. J. Minchiner, "high temperature corrosion in fluidized bed combustion system", Journal of metals, Vol. 36, No. 7, pp. 20-21, 1994.

[30] I. Obernberger, "Concentrations of inorganic elements in biomass fuels and recovery in the different ash fractions", biomass and bioenergy, Vol. 36, No. 6, pp. 410, 1997.

[31] L.M. Romeo, R. Gareta, "Hybrid System for fouling control in biomass boilers", Eng Appl Artif Intell. , Vol.19, No. 9, pp.15-25, 2006.

[32] L.M. Romeo, and R. Gareta, "Fouling control in biomass boilers", Biomass and bioenergy, Vol. 33, No. 8, pp .854-61, 2009.

[33] R. R. Bakker, "Biomass fuel leaching for the control of fouling, 
slagging, and agglomeration in biomass power greneration" PHD Thesis, University of California, 2000.

[34] V. Barisic, L. Amand, and C. E. Zabetta, "The role of limestone in preventing agglomeration and slagging during CFB combustion of high- phosphorous fuels", http://fwcparts.com/publicat ions/tech papers/files/TP CFB 08 03.pdf; 2008 [accessed 10.07.18].

[35] R. W. Bryers, "Fireside slagging, fouling and high-temperature corrosion of heat transfer surface due to impurities in steam raising fuels", Progress in Energy and Combustion Science, Vol.22, pp. 29-120, 1996.

[36] W. Lin, K. Dam -Johansen, F. Frandsen, "Agglomeration in biofuel fired fluidized bed combustion", Chemical Engineering journal, Vol. 96, pp. 171-185, 2003.

[37] M. J. F. Llorente, J. M. M. Laplaza, R. E. Cuadrado, J. E. C. Garcia, "Ash behaviour of lignocellulosic biomass in bubbling fluidized bed combustion", Fuel, Vol. 85, pp. 1157-1165, 2006.

[38] B.M. Jenkins, L. L. Baxter, T. R. Miles Jr, L. L. Oden, R. W. Bryers, "Composition of ash deposits in biomass fueled boilers: results of full scale experiments and laboratory simulations", International ASME Summer Meeting. Kansas City, USA. pp. 19-24, 1994.

[39] B. Olanders, and B. M. Steenari, "Characterization of ashes from wood and straw", Biomass and Bioenergy, Vol.8, pp. 105-115.,
1995.

[40] J. Silvennoinen, "A new method to inhibit bed agglomeration problems in fluidized bed boilers", FBC 2003, 17th international Fluidized Bed Combustion Conference. Florida, USA, pp. 1-9, 2003.

[41] J. Daavitsainen, R. Laitinen, L. Nuutinen, H. Ollila, M. Tiainen, M. Virtanen, "Effect of GR GRANULE used as bed material to reduce agglomeration in BFB combustion of biomass with high alkali meta content", Progress in Thermochemical Biomass Conversion, pp. 705$712,2001$.

[42] R. Laitinen, L. Nuutinen, M. Tiainen, M. Virtanen, "An improved bed material for BFB boilers, Case 2: combustion of fuel with high sodium content", 5th European Conference on Industrial Furnaces and Boilers. Porto, Portugal, pp. 1-6, 2000.

[43] T. Lind, T. Valmari, E. I. Kauppinen, G. Sfiris, K. Nilsson, W. Maenhaut, "Volatilization of the heavy metals during circulating fluidized bed combustion of forest residue", Environmental Science \& Technology, Vol. 33, No. 3, pp. 496-502, 1999.

[44] M. Uberoi and F. Shadman, "Aluminosilicates as potential sorbents for controlling metal emissions", ACS Symposium, Vol. 515, pp. 214222, 1993. 